\title{
Períodos de Interferência de uma Comunidade de Plantas Daninhas na Cultura da Batata ${ }^{1}$
}

\author{
Weed Interference Periods in Potato Crop
}

COSTA, N.V. ${ }^{2}$, CARDOSO, L.A. ${ }^{3}$, RODRIGUES, A.C.P. ${ }^{3}$ e MARTINS, D. ${ }^{4}$

\begin{abstract}
RESUMO - Objetivou-se neste trabalho avaliar diferentes períodos de controle e de convivência de uma comunidade de plantas daninhas na cultura da batata 'Atlantic'. O experimento foi realizado no municipio de Botucatu-SP, e o delineamento experimental utilizado foi de blocos ao acaso com quatro repetições. Os tratamentos constituíram-se de seis periodos de controle, nos quais a cultura foi mantida livre da comunidade de plantas daninhas e após cada período, as plantas daninhas foram deixadas crescer livremente; e de seis periodos de convivência, nos quais a cultura foi mantida na presença da comunidade de plantas daninhas e após cada periodo, as plantas daninhas foram eliminadas até a colheita. Os períodos foram de $7,14,21,28,35$ e 42 dias após o plantio dos tubérculos, além de uma testemunha mantida sempre livre de plantas daninhas e outra mantida sempre na presença dessas plantas. Foram identificadas 9 famílias e 15 espécies de plantas daninhas, com destaque para Bidens pilosa, Galinsoga parviflora, Brachiaria plantaginea, Commelina benghalensis e Digitaria horizontalis. Os resultados de produção de tubérculos ajustaram-se ao modelo de regressão não-linear: y = 8,907+(17,722/[1+(x/16,865 $\left.\left.)^{-8,412}\right]\right)$, $\left(\mathrm{R}^{2}=0,963^{*}\right)$ - equação para os períodos de controle e y $=5,728+\left(24,789 /\left[1+(\mathrm{x} / 39,292)^{2,247}\right]\right)$, $\left(R^{2}=0,947^{*}\right)$ - equação para os periodos de convivência. Assim, considerando perda de $5 \%$ na produtividade como aceitável, foram determinados o período anterior à interferência (PAI), que foi de 20 dias; o periodo total de prevenção à interferência (PTPI), de 21 dias; e o período crítico de prevenção da interferência (PCPI), de apenas de um dia, dos 20 aos 21 dias após o plantio dos tubérculos.
\end{abstract}

Palavras-chave: Solanum tuberosum, matointerferência, competição, Atlantic.

\begin{abstract}
The aim of this research was to evaluate different weed control periods and weed coexistence periods in the potato crop 'Atlantic'. The experiment was carried out in Botucatu-SP, Brazil. The experimental design was a randomized complete block with four replications and the treatments consisted of six control periods, with weed free crop. After each period the weeds were allowed to grow freely and after six coexistence periods, and after each period, the weeds were eliminated until harvest. The periods were established in 7, 14, 21, 28, 35 and 42 days after tubers were sown, besides a control maintained weed free and another maintained in coexistence with the weeds. Nine families and 15 species were identified, with Bidens pilosa, Galinsoga parviflora, Brachiaria plantaginea, Commelina benghalensis being the most prominent Tuber production results were adjusted to the non-linear regression model: $y=8.907+(17.722)$ $\left.\left[1+(x / 16.865)^{-8,412}\right]\right),\left(R^{2}=0.963^{*}\right)$ equation for the control periods and $y=5.728+(24.789 /[1+(x)$ 39.292) $\left.\left.)^{2,247}\right]\right),\left(R^{2}=0.947^{*}\right)$ equation for the coexistence periods. Thus, considering a loss of $5 \%$ in productivity as acceptable, it was possible to determine that the period previous to interference (PPI) was 20 days; the total period of weed interference (TPWI), was 21 days and the critical period of weed interference (CPWI), was just one day, from 20 to 21 days after tuber planting.
\end{abstract}

Keywords: Solanum tuberosum, weed interference, competition, Atlantic crop.

1 Recebido para publicação em 14.5.2007 e na forma revisada em 4.1.2008

2 Doutor em Agronomia/Agricultura <neumarciovc@ hotmail.com>; ${ }^{3}$ Doutorando em Agronomia do Departamento de Produção Vegetal da FCA-UNESP, Botucatu/SP; ${ }^{4}$ Prof. Adjunto do Dep. de Produção Vegetal da FCA-UNESP, Fazenda Lageado, Caixa Postal 237, 18603-970, Botucatu-SP.

Planta Daninha, Viçosa-MG, v. 26, n. 1, p. 83-91, 2008 


\section{INTRODUÇÃO}

O conhecimento da capacidade de interferência de plantas daninhas sobre as culturas é importante na tomada de decisão para realização do controle (Vidal et al., 2004). Entretanto, o balanço competitivo entre as comunidades infestantes e as culturas agrícolas depende de fatores ligados à própria comunidade infestante (composição específica, densidade e distribuição), à cultura (espécie ou variedade, espaçamento e densidade de plantio) e à época de extensão do período de convivência, os quais podem ser alterados pelas condições edafoclimáticas e pelos tratos culturais. Nesse contexto, a densidade de plantas e a época e extensão do periodo de convivência destacam-se em importância, uma vez que estarão diretamente envolvidas nas tomadas de decisões quanto à utilização de herbicidas (Pitelli, 1985; Locke et al., 2002).

Vários pesquisadores verificaram que a convivência da comunidade de plantas daninhas com a cultura da batata pode reduzir a produção de tubérculos em cerca de 6,4 a 65\% (Jaiswal, 1992; Beltrano \& Caldiz, 1993; Muhammad, 1993; Liebman et al., 1996; Ciuberkis et al., 2007).

Vangessel \& Renner (1990) ressaltam que a interferência das plantas daninhas na cultura da batata pode influenciar a qualidade dos tubérculos, tornando-os menores e alterando sua densidade, além de causar deformações, diminuindo o seu valor de mercado. O controle das plantas daninhas destaca-se como um essencial componente da produção agrícola (Zoschke \& Quadranti, 2002). Assim, o estudo da integração de diferentes estratégias de manejo de plantas daninhas torna-se importante no desenvolvimento de um sistema de produção sustentável e eficiente.

Para implementação de programas de manejo integrado de plantas daninhas, é imprescindivel estudar os períodos de convivência possivel entre as plantas invasoras e a planta cultivada, além de requerer apurado conhecimento na predição da emergência das sementes e do impacto das plantas daninhas sobre a cultura (Ciuberkis et al., 2007).

Dessa forma, conforme proposto por Pitelli \& Durigan (1984), o objetivo deste trabalho foi determinar o período em que a cultura da batata ('Atlantic') pode permanecer em convivência com uma comunidade de plantas daninhas sem haver interferência negativa em sua produção final (PAI = Período Anterior à Interferência), bem como determinar o periodo a partir do plantio em que a cultura deve permanecer livre da presença das plantas daninhas para que não ocorram perdas de produção $(\mathrm{PTPI}=$ Período Total de Prevenção da Interferência). A partir do estudo desses dois períodos, pode-se determinar também o período em que efetivamente os métodos de controle devem ser realizados para minimizar as perdas de produtividade (PCPI = Período Crítico de Prevenção da Interferência).

\section{MATERIAL E MÉTODOS}

O experimento foi realizado no Núcleo de Pesquisas Avançadas em Matologia-NUPAM, pertencente ao Departamento de Produção Vegetal-DPV da Faculdade de Ciências Agronômicas-FCA/UNESP, campus de Botucatu-SP.

O plantio dos tubérculos foi realizado em 8/8/2005, em uma área de solo argiloso, classificado como Nitossolo Vermelho Estruturado (Embrapa, 1999), com as seguintes características: $\mathrm{pH}\left(\mathrm{CaCl}_{2}\right)=4,7$; matéria orgânica $\left(\mathrm{g} \mathrm{dm}^{-3}\right)$ $=21,5 ; \mathrm{P}\left(\mathrm{mg} \mathrm{dm}^{-3}\right)=12,6 ; \mathrm{H}+\mathrm{Al}, \mathrm{K}, \mathrm{Ca}, \mathrm{Mg}, \mathrm{SB}$ e CTC $\left(\mathrm{mmol}_{\mathrm{c}} \mathrm{dm}^{-3}\right)=54,7 ; 3,0 ; 16,5 ; 4,4 ; 23,8 \mathrm{e}$ 78,5 ; respectivamente; e $\mathrm{V} \%=30,3$.

Foram realizadas na área experimental duas arações, sendo uma com arado de aiveca e a outra com grade pesada, além de duas operações com grade niveladora. Foram aplicados 3,5 t ha ${ }^{-1}$ de calcário dolomítico e $1,0 \mathrm{t} \mathrm{ha}^{-1} \mathrm{de}$ termofosfato Yorin, 2,0 t ha ${ }^{-1}$ da fórmula 8-2816 , que foram distribuídos em área total e incorporados ao solo com auxílio de uma grade niveladora, para homogeneização da área. Foram plantados tubérculos do cultivar 'Atlantic' em parcelas de quatro linhas de $5 \mathrm{~m}$ de comprimento, com espaçamento de 0,7 m entre linhas e de 0,25 m entre plantas. Foram consideradas como área útil as duas linhas centrais de cada parcela. A emergência das plantas daninhas e a brotação das hastes dos tubérculos (>70\%) ocorreram aos 4 e 20 dias após o plantio (DAP), respectivamente.

O delineamento experimental utilizado foi o de blocos ao acaso, com quatro repetições. 
Os tratamentos constituíram-se de seis períodos crescentes de controle das plantas daninhas $(7,14,21,28,35$ e 42 DAP) e de seis períodos de convivência entre a comunidade infestante e a cultura $(7,14,21,28,35$ e 42 DAP) no início do desenvolvimento, a partir do plantio dos tubérculos, além de uma parcela mantida livre das plantas daninhas (testemunha no limpo) e outra com estas plantas (testemunha no mato), até o final do estudo. Os períodos de controle e de convivência apresentaram intervalos de sete dias e foram avaliados até próximo da realização da amontoa, aos 42 DAP neste momento também foi realizada uma cobertura de $\mathrm{N}\left(80 \mathrm{~kg} \mathrm{ha}^{-1}\right)$.

O controle das plantas daninhas no final de cada período de convivência e para os períodos de controle foi realizado por meio de capinas manuais, sendo as parcelas mantidas no limpo até o momento da colheita (90 DAP). Para caracterização e estudo fitossociológico da comunidade infestante, foi utilizado como unidade amostral um quadro (0,5 x 0,5 m), o qual foi lançado aleatoriamente dentro de cada parcela no final de cada período de convivência. Em cada quadro amostrado, as plantas daninhas foram contadas e identificadas, segundo família, espécie e nome vulgar.

A partir da contagem das espécies presentes, foram calculadas as seguintes variáveis fitossociológicas: densidade (D), densidade relativa (Dr), freqüência $(F)$, freqüência relativa (Fr), abundância (A), abundância relativa (Ar) e índice de importância relativa (Ir), calculados conforme a fórmula proposta por MuellerDombois \& Ellemberg (1974). No momento da colheita foram realizadas avaliações referentes à produção de batata, sendo esta expressa em porcentagem das produções dos tubérculos com diâmetro maior e menor que $50 \mathrm{~mm}$, seguindo o proposto por Vangessel \& Renner (1990).

Na determinação dos períodos de interferência foi utilizado o método proposto por Kozlowski et al. (2002). Os dados de produção obtidos nos diferentes períodos de controle e de convivência foram ajustados ao modelo de regressão não-linear, por meio do programa SigmaStat 2.0, usando a equação logística:

$$
y=a+\frac{b}{\left[1+\left(x / c^{d}\right)\right]}
$$

em que:

$\mathrm{y}=$ produção de tubérculos;

$\mathrm{x}=$ dias após o plantio;

$\mathrm{a}=$ produção mínima no início do ensaio para os períodos de controle e no final do ensaio para os períodos de convivência;

$\mathrm{b}=$ diferença entre a produção máxima e a mínima;

$\mathrm{c}=\mathrm{n}^{\circ}$ de dias em que ocorreu $50 \%$ de redução na produção máxima de tubérculos; e

$\mathrm{d}=$ declividade da curva.

O início do período crítico de prevenção da interferência (PCPI), identificado pelo final do período anterior à interferência (PAI) no modelo para os períodos de convivência, foi calculado subtraindo-se a diferença mínima significativa (DMS a 5\% de probabilidade), obtida após a comparação das médias de produção dos tratamentos (períodos de controle e de convivência) pelo teste LSD a $5 \%$, da média do rendimento máximo para o respectivo modelo. $\mathrm{O}$ resultado foi substituído em $y$ da equação logística, obtendo-se assim o valor de $x$, que identifica o número de dias após o plantio dos tubérculos em que se iniciou o PCPI.

O final do PCPI coincide com o final do período total de prevenção da interferência (PTPI) verificado no modelo para os períodos de controle, sendo obtido subtraindo-se a diferença mínima significativa (DMS a 5\% de probabilidade), obtida após comparação das médias de produção dos tratamentos (períodos de controle e de convivência) pelo teste LSD, da média do rendimento máximo para o respectivo modelo. $O$ resultado foi substituído em $y$ da equação logística, obtendo-se assim o valor de $x$, que identifica o número de dias após o plantio dos tubérculos em que terminou o PCPI.

Os resultados expressos em porcentagem para as produções dos tubérculos com diâmetro maior e menor que $50 \mathrm{~mm}$, bem como para a porcentagem de redução da produção em função dos períodos de controle e de convivência, foram submetidos à análise estatística de regressão, sendo as equações escolhidas com base nos modelos significativos, com lógica biológica e de elevado $\mathrm{R}^{2}$. 


\section{RESULTADOS E DISCUSSÃO}

Foram identificadas 9 famílias e 15 espécies, com predominância da classe Magnoliopsida (Dicotyledoneae) (60\%). Destacaram-se as familias Asteraceae e Poaceae com maior número de espécies, quatro em cada família (Tabela 1).

As plantas daninhas iniciaram a emergência das plântulas aos 4 dias após o plantio (DAP); aos 7 DAP a comunidade de plantas daninhas se apresentava praticamente estabelecida na área experimental (Figura 1). Entretanto, no geral houve cerca de $42,3 \%$ mais plantas daninhas por metro quadrado nos tratamentos referentes aos períodos de convivência, em relação aos referentes aos períodos de controle.

A comunidade de plantas daninhas atingiu as maiores densidades a partir dos 14 DAP (249 plantas $\mathrm{m}^{-2}$ ) e aos 28 DAP (433 plantas $\mathrm{m}^{-2}$ ), para os períodos de controle e de convivência, respectivamente. Contudo, verificou-se para os períodos de controle em que o manejo das plantas daninhas foi de pelo menos 21 DAP, que ocorreram reduções na emergência do banco de sementes e, conseqüentemente, diminuição da densidade das plantas daninhas em torno de $27,7 \%$ na área, mantendo-se níveis baixos de reinfestação ao longo de todo o ciclo da cultura, em relação ao tratamento que conviveu com a comunidade de plantas daninhas do plantio até a colheita. Esse efeito foi mais pronunciado quando o controle das plantas daninhas foi realizado até os 35 e 42 DAP, com redução nas densidades das plantas daninhas na ordem de 86,6 e $80,6 \%$, respectivamente. Da mesma forma, para os períodos de convivência a partir dos 28 DAP, verificou-se decréscimo na densidade das plantas daninhas até o final do ciclo da cultura.

Na Figura 2 está demonstrado o índice de valor de importância (IVI) das plantas daninhas presentes em cada tratamento, para os periodos de controle e de convivência.

Apesar de as espécies da classe Liliopsida (Monocotyledoneae) representarem apenas $40 \%$ do total das espécies identificadas na área experimental, para os tratamentos referentes aos periodos de controle, estas demonstraram os maiores IVI, destacando-se Brachiaria plantaginea, Commelina benghalensis e Digitaria horizontalis. Por outro lado, dentre as espécies da classe Magnoliopsida (Dicotyledoneae), destacaram-se Bidens pilosa e Galinsoga parviflora.

De maneira geral, as espécies $B$. plantaginea $e C$. benghalensis foram as mais predominantes, apresentando em média 45,7 e $69,4 \%$ de IVI, respectivamente. No experimento, verificou-se que, dentre as espécies predominantes, $B$. pilosa, B. plantaginea, $C$. benghalensis, $D$. horizontalis e G. parviflora foram as que apresentaram o maior poder de competição após o período de controle de 21 DAP, destacando-se $C$. benghalensis, que apresentou o maior IVI $(87,0 \%)$, em relação às demais espécies no mesmo período. Entretanto, aos 35 DAP, G. parviflora não foi identificada, assim como, aos $42 \mathrm{DAP}$, as espécies $D$. horizontalis e $G$. parviflora também não foram encontradas. Provavelmente, a cultura e as espécies que conseguiram emergir após os respectivos períodos de controle exerceram efeito supressivo sobre essas espécies, devido a redução da passagem de luz até o solo, o que pode ter inibido a germinação das sementes e/ou prejudicando o desenvolvimento das plântulas que emergiram.

Da mesma forma, verificou-se que as espécies $B$. pilosa, $B$. plantaginea, $C$. benghalensis e $D$. horizontalis foram as que apresentaram o maior poder de competição a partir do período de convivência de 14 DAP, destacando-se $D$. horizontalis, que apresentou o maior IVI $(95,1 \%)$, em relação às demais espécies no mesmo período. Entretanto, a partir dos 35 DAP houve diminuição do valor do IVI da espécie $D$. horizontalis e aumento do IVI de G. parviflora, sendo essa inversão mais evidente no momento da colheita.

As espécies de plantas daninhas identificadas neste trabalho e que apresentaram os maiores valores de IVI também foram citadas como plantas daninhas importantes em culturas como milho, soja e feijão (Kozlowski et al., 2002; Kozlowski, 2002; Vidal et al., 2004). Essas culturas são utilizadas em rotação em áreas de produção de tubérculos de batata. Dentre as espécies de maior ocorrência nestas áreas, destacam-se $B$. plantaginea, $C$. benghalensis, D. horizontalis e B. pilosa. 
Períodos de interferência de uma comunidade de plantas...

Tabela 1 - Relação das plantas daninhas presentes na área experimental por família, espécie e nome vulgar

\begin{tabular}{|c|c|c|}
\hline Família & Espécies & Nome vulgar \\
\hline \multicolumn{3}{|c|}{ Magnoliopsida } \\
\hline Amaranthaceae & Amaranthus lividus L. & Caruru \\
\hline \multirow{4}{*}{ Asteraceae } & Acanthospermum australe (Loef.) Kuntze & Carrapicho-preto \\
\hline & Bidens pilosa $\mathrm{L}$. & Picão-preto \\
\hline & Emilia sonchifolia L. DC. & Falsa-serralha \\
\hline & Galinsoga parviflora Cav. & Picão-branco \\
\hline Brassicaceae & Raphanus sativus L. & Nabiça \\
\hline Oxalidaceae & Oxalis latifolia $\mathrm{L}$. & Trevo-azedo \\
\hline Portulacaceae & Portulaca oleracea $\mathrm{L}$. & Beldroega \\
\hline Solanaceae & Solanum amercanum Mill. & Maria-preta \\
\hline \multicolumn{3}{|c|}{ Liliopsida } \\
\hline Commelinaceae & Commelina benghalensis $\mathrm{L}$. & Trapoeraba \\
\hline Cyperaceae & Cyperus esculentus $\mathrm{L}$. & Tiririca \\
\hline \multirow{4}{*}{ Poaceae } & Brachiaria plantaginea (Link) Hitchc. & Capim-marmelada \\
\hline & Cenchrus echinatus $\mathrm{L}$. & Capim-carrapicho \\
\hline & Digitaria horizontalis Willd. & Capim-colchão \\
\hline & Eleusine indica (L.) Gaert. & Capim-pé-de-galinha \\
\hline
\end{tabular}

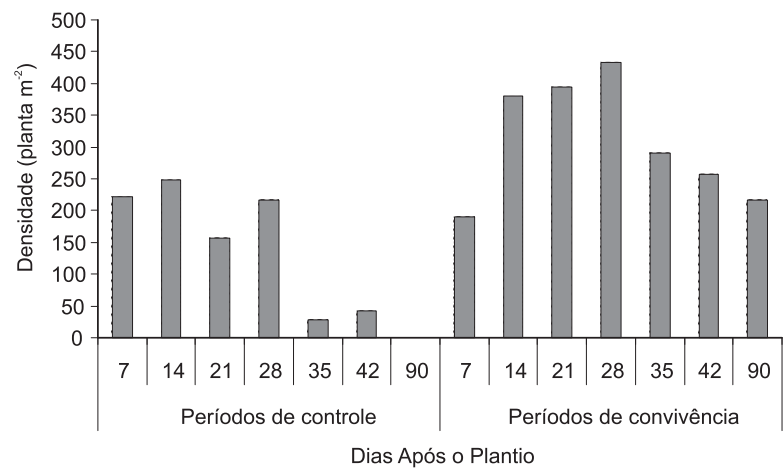

Figura 1 - Densidade das plantas daninhas presentes em cada tratamento para os períodos de controle e de convivência.

Os resultados da produção de tubérculos de batata podem ser verificados analisandose a Figura 3. Dessa forma, o período anterior à interferência (PAI) foi determinado utilizando-se a equação:

$$
\mathrm{y}=5,728+\frac{24,789}{\left[1+(\mathrm{x} / 39,292)^{2,247}\right]}
$$

referente à curva dos dados de produção dos períodos de convivência, e o período total de prevenção de interferência (PTPI) foi determinado utilizando-se a equação:

$$
y=8,907+\frac{17,722}{\left[1+(x / 16,865)^{-8,412}\right]}
$$

referente à curva dos dados de produção dos períodos de controle.

Ao comparar as médias dos tratamentos, pelo teste LSD a $5 \%$ de probabilidade, dentro do mesmo modelo de interferência, dos períodos de controle e de convivência, observou-se que o valor da diferença mínima significativa $(p<0,05)$ foi de $4,32 \mathrm{t} \mathrm{ha}^{-1}$, o que permitiu estimar produções iguais a $26,03 \mathrm{t} \mathrm{ha}^{-1}(30,35-$ $4,32)$ e 24,15 t ha $^{-1}(28,47-4,32)$ para os modelos de períodos de convivência e de controle, respectivamente, os quais não diferiram estatisticamente entre si. Assim, com base nos dados de produção, foi possivel calcular o período crítico de prevenção da interferência (PCPI), conforme as equações a seguir:

Para o modelo dos períodos de convivência:

$$
26,03=5,728+\frac{24,789}{\left[1+(x / 39,292)^{2,247}\right]}
$$

em que $x$ corresponde a quando, em dias, termina o PAI ou se inicia o PCPI.

Para o modelo dos períodos de controle:

$$
24,15=8,907+\frac{17,722}{\left[1+(\mathrm{x} / 16,865)^{-8,412}\right]}
$$

em que $x$ corresponde a quando, em dias, terminam o PTPI e o PCPI.

Planta Daninha, Viçosa-MG, v. 26, n. 1, p. 83-91, 2008 


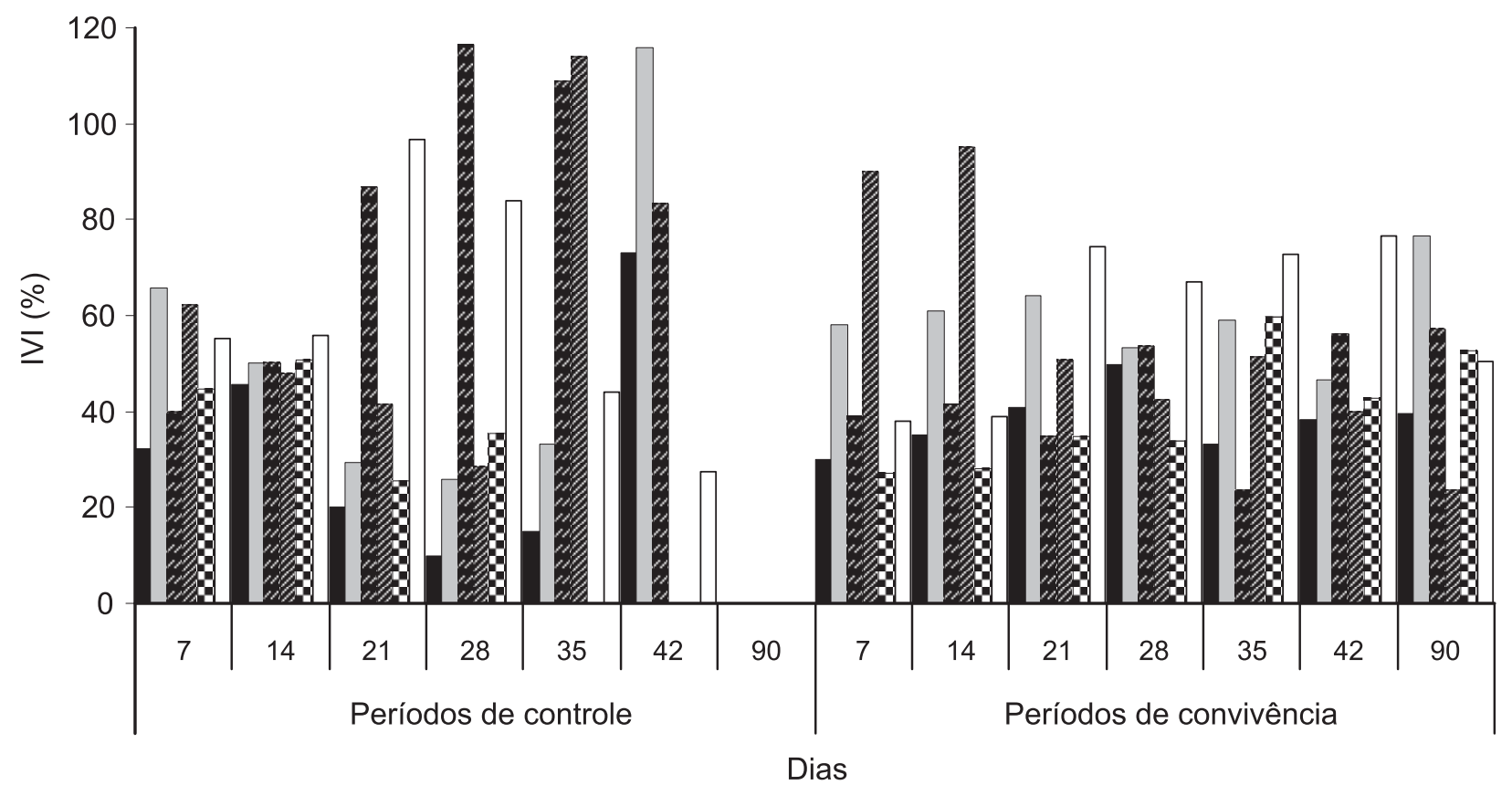

B. pilosa $\square$ B. plantaginea $\square$ C. benghalensis $\mathscr{D}$. horizontalis $\square$ G. parviflora $\square$ Outras

Figura 2 - Índice de Valor de Importância (IVI) das plantas daninhas presentes em cada tratamento para os períodos de controle e de convivência.

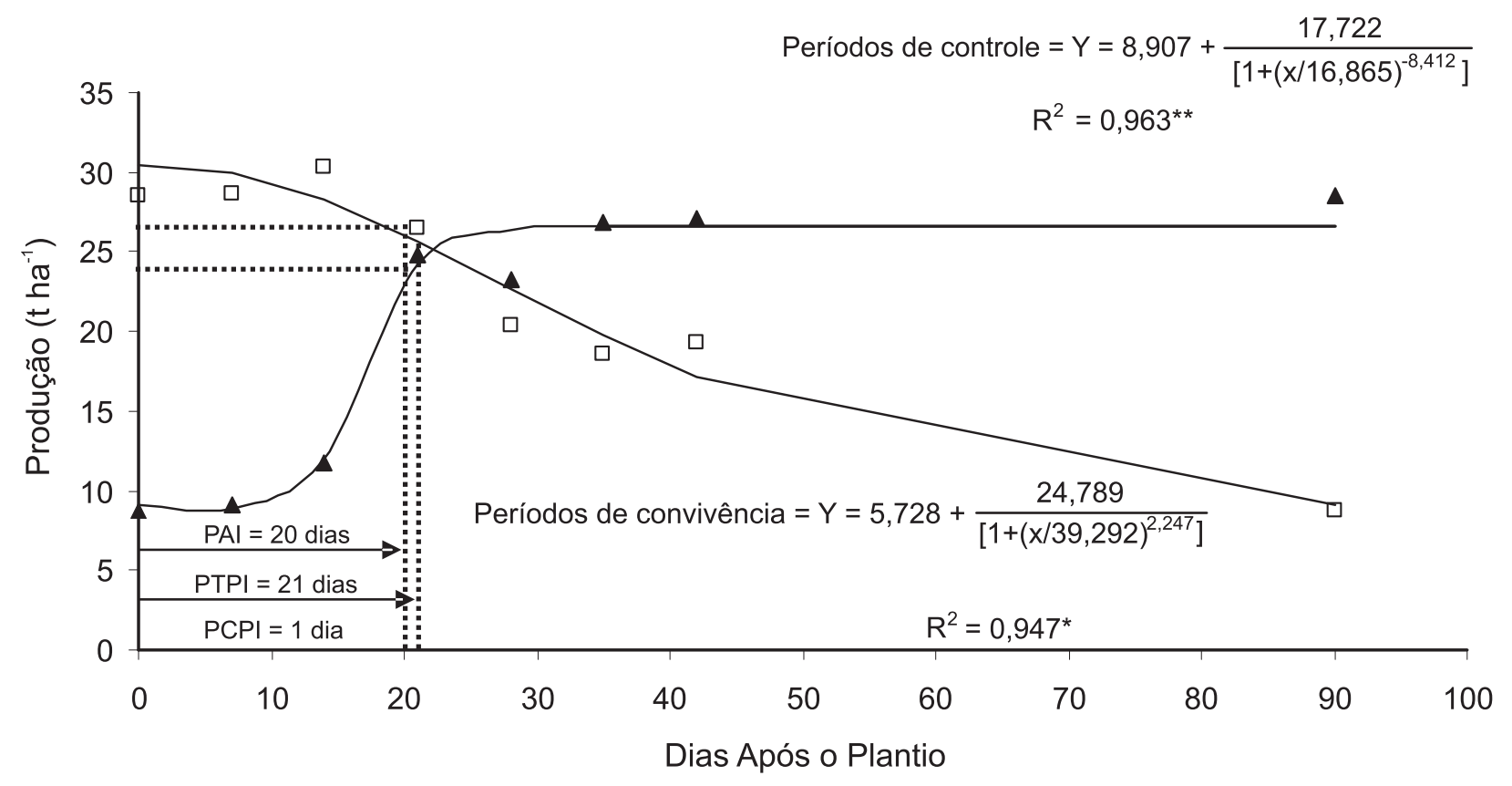

$\Delta$ Períodos de controle $\square$ Períodos de convivência

Figura 3 - Produção de tubérculos de batata em função dos períodos de controle e de convivência com as plantas daninhas. 
Os valores de $x$ corresponderam a 20,06 e 20,93 dias, para os modelos dos períodos de convivência e de controle, respectivamente. Esses resultados indicam que a cultura da batata ('Atlantic') pode permanecer em convivência com a comunidade de plantas daninhas sem interferência negativa acima de $5 \%$ na produção final por aproximadamente 20 dias $(\mathrm{PAI}=20$ dias); e que o periodo a partir do plantio em que a cultura da batata ('Atlantic') deve permanecer livre da presença das plantas daninhas para que não ocorram perdas de produção acima de $5 \%$ é de aproximadamente 21 dias (PTPI = 21 dias).

Desse modo, pode-se verificar que o PAI foi menor que o PTPI, e o intervalo entre esses dois períodos define o período crítico de prevenção da interferência (PCPI), durante o qual as práticas de controle devem ser efetivamente realizadas. Portanto, o PCPI para a cultura da batata ('Atlantic') foi de aproximadamente um dia. Entretanto, de acordo com Jaiswal (1992), para a cultura da batata o PCPI está compreendido entre 25 e 35 DAP; após esse período, a convivência da comunidade de plantas daninhas com a cultura pode promover redução da produção de tubérculos na ordem de $31 \%$.

O PCPI de apenas um dia pode implicar uma série de dificuldades ou impossibilidades na execução da operação de controle da comunidade das plantas daninhas, principalmente em áreas bastante extensas e em condições de clima desfavorável ao manejo. Em razão disso, uma única eliminação da comunidade das plantas daninhas no término do PAI ou do PTPI seria necessário para que a cultura pudesse expressar completamente todo o seu potencial produtivo (Velini, 1997), sem que haja perdas acima de $5 \%$.

A aplicação de herbicidas em pós-emergência com ou sem efeito residual no PCPI, bem como o método de controle pela utilização de cultivadores no período da amontoa, além do sistema de rotação de culturas e que utiliza a cobertura morta combinada com herbicidas, destacariam-se como excelentes alternativas de manejo da comunidade de plantas daninhas na cultura da batata (Liebman et al., 1996; Eberlein et al., 1997; Bellinder et al., 2000; Bailey et al., 2001; Boydston \& Vaughn, 2002; Hutchinson et al., 2003). Desta maneira, Knezevic et al. (2002) e Zoschke \& Quadranti
(2002) ressaltam que o manejo integrado de plantas daninhas com o uso de diferentes técnicas para prever os problemas causados por essas espécies e, assim, antecipar o manejo principalmente quando já estão presentes, convivendo com a cultura poderia contribuir para prevenção de produção de semente e reduzir a germinação, além de minimizar a competição entre as plantas daninhas e a cultura, porém sem eliminar completamente as plantas invasoras.

Em algumas situações, a presença de plantas daninhas convivendo com a cultura da batata pode proporcionar aumento na produtividade, como foi observado para os períodos de convivência de 7 e 14 DAP, que evidenciaram aumentos da produção de tubérculos na ordem de 0,75 e $6,59 \%$, respectivamente, em relação à testemunha totalmente no limpo.

Na Figura 4 estão representadas as curvas de regressão polinomial referentes à porcentagem de tubérculos com diâmetro $>50 \mathrm{~mm}$ e $<50 \mathrm{~mm}$ em função dos períodos de controle e, na Figura 5, as curvas de regressão polinomial referentes à porcentagem de tubérculos com diâmetro $>50 \mathrm{~mm}$ e $<50 \mathrm{~mm}$, em função dos períodos de convivência. Nota-se que os dados obtidos ajustaram-se à equação polinomial quadrática e apresentaram elevado $R^{2}$.

Considerando o PTPI de 21 dias, verificase que a relação da porcentagem de tubérculos com diâmetro $>50 \mathrm{~mm} \mathrm{e}<50 \mathrm{~mm}$ foi na ordem de 75,56 e 24,44\%, respectivamente (Figura 4). Já para o PAI de 20 dias a relação da porcentagem de tubérculos com diâmetro $>50 \mathrm{~mm}$ e $<50 \mathrm{~mm}$ foi em torno de 81,72 e 18,28\%, respectivamente (Figura 5). Esses resultados

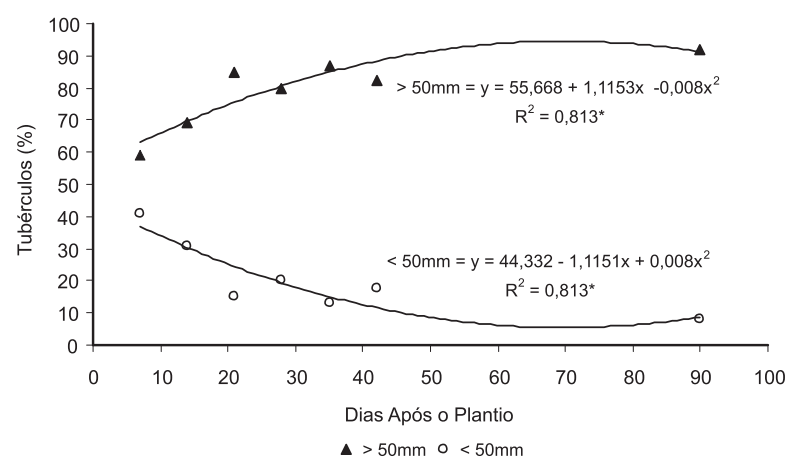

Figura 4 - Porcentagem de tubérculos com diâmetro $>50 \mathrm{~mm}$ e $<50 \mathrm{~mm}$, em função dos períodos de controle.

Planta Daninha, Viçosa-MG, v. 26, n. 1, p. 83-91, 2008 


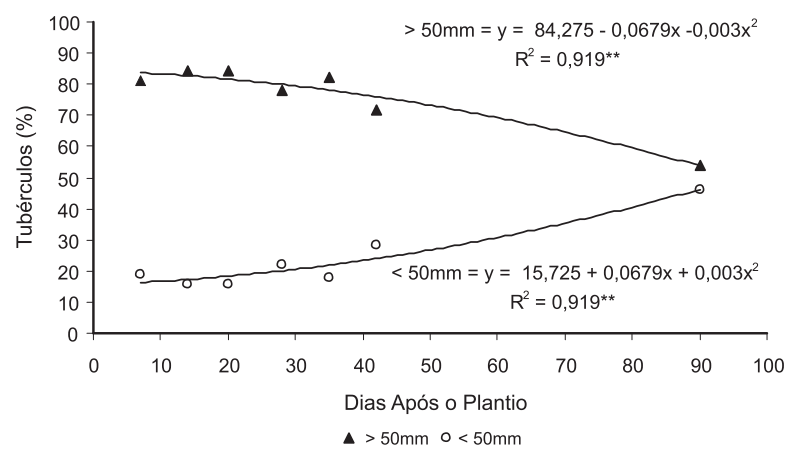

Figura 5 - Porcentagem de tubérculos com diâmetro $>50 \mathrm{~mm}$ e $<50 \mathrm{~mm}$, em função dos períodos de convivência.

reforçam a necessidade de realização do controle da comunidade das plantas daninhas, principalmente no término do PAI.

A porcentagem de tubérculos com diâmetro $>50 \mathrm{~mm} \mathrm{e}<50 \mathrm{~mm}$, obtida nas parcelas que estiveram na ausência total das plantas daninhas (testemunha no limpo) em comparação com as obtidas nas parcelas que conviveram com as plantas daninhas durante todo o ciclo (testemunha no mato), foi reduzida em cerca de $40,97 \%$ e aumentada em torno de $425,89 \%$, respectivamente. Quando a cultura conviveu por 90 dias com a comunidade de plantas daninhas, a porcentagem de tubérculos com diâmetro $>50 \mathrm{~mm} \mathrm{e}<50 \mathrm{~mm}$ foi de 53,86 e $46,14 \%$, respectivamente, o que prejudicou drasticamente a qualidade dos tubérculos para comercialização. Vangessel \& Renner (1990) evidenciaram que a competição de quatro plantas de Echinochloa crusgalli ou de Amaranthus retroflexus presentes na linha ou entre linhas da cultura durante todo o ciclo não reduziu a porcentagem de tubérculos com diâmetro $>50 \mathrm{~mm}$ para o cv. Atlantic. Contudo, estas espécies reduziram a densidade dos tubérculos comercializáveis em torno de 33,3 e 50,0\%, respectivamente. Ressalta-se que a competição entre as plantas daninhas e a cultura depende da espécie da planta daninha e da sua abundância relativa (Pitelli, 1985; Ciuberkis et al., 2007).

Segundo Ciuberkis et al. (2007), a competição da comunidade de plantas daninhas formada por Viola arvensis, Tripleurospermum perforatum, Capsella bursa-pastoris e Polygonum lapathifolium com a cultura da batata ('Mirta') reduziu a produção de tubérculos em cerca de
$8,1 \%$, quando conviveram com a cultura por um período de 74 dias após o plantio, na densidade de 42 plantas $\mathrm{m}^{-2}$. Do mesmo modo, Beltrano \& Caldiz (1993) citam que a espécie Sorghum halepense convivendo com a cultura da batata ('Primicia') até a colheita, na densidade acima de 17 planta $\mathrm{m}^{-2}$, pode reduzir o peso e a produção de tubérculos em mais de 80 e $45 \%$, respectivamente. Já o efeito competitivo de 5 plantas $\mathrm{m}^{-2}$ de Chenopodium album pode reduzir a produção de tubérculos de batata em 43\% (Everaarts \& Satsyati, 1978 apud Ciuberkis et al., 2007). Muhammad (1993) concluiu que a convivência da comunidade de plantas daninhas com a cultura da batata por um período de 49 DAP reduziu a produção de tubérculos em torno de $43 \%$, em relação à testemunha no limpo.

Ao comparar as produções de tubérculos obtidas nas parcelas das testemunhas no limpo com as produções das parcelas das testemunhas no mato, verificou-se que a comunidade de plantas daninhas que apresentou no momento da colheita densidade de 216,0 plantas $\mathrm{m}^{-2}$ (Figura 1) reduziu a produção de tubérculos do cv. Atlantic em 69,6\% (Figura 6). Do mesmo modo, quando o cv. Atlantic permaneceu apenas 7,14 e 21 dias no limpo, a comunidade de plantas daninhas apresentou no momento da colheita densidades de 220,0, 249,0 e 156,0 plantas $\mathrm{m}^{-2}$, respectivamente, acarretando redução da produção de tubérculos em 59,6, 43,8 e 29,9\%, respectivamente.

Resultados semelhantes foram obtidos por Vangessel \& Renner (1990) para o mesmo cultivar; estes pesquisadores demonstraram que a competição de quatro plantas de $A$. retroflexus ou de $E$. crusgalli presentes na linha ou entre linhas da cultura durante todo o ciclo pode reduzir a produção de tubérculos em cerca de 2,5 a $40 \%$.

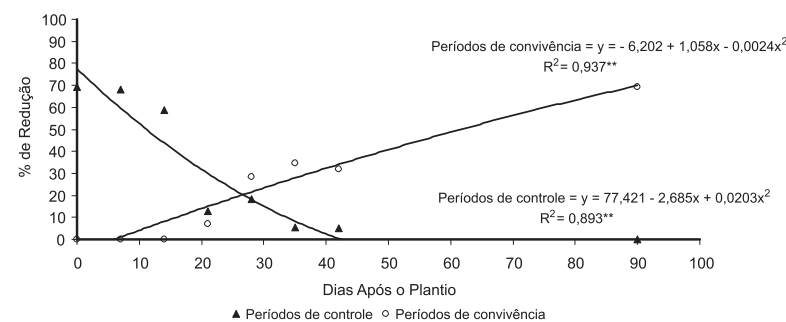

Figura 6 - Porcentagem de redução da produção de tubérculos, em função dos períodos de controle e de convivência. 
Dessa forma, considerando a perda de $5 \%$ na produtividade como aceitável, foi possível determinar o período anterior à interferência (PAI), que foi de 20 dias; o período total de prevenção à interferência (PTPI), de 21 dias; e o período crítico de prevenção da interferência (PCPI), de apenas de um dia, dos 20 aos 21 dias após o plantio.

No entanto, constata-se que o efeito da interação da competição entre a comunidade de plantas daninhas e a cultura da batata pode apresentar-se extremamente variável. Essa interação está correlacionada com as espécies de plantas daninhas presentes na comunidade infestante, com o tipo de cultivar e também com as características do meio. Segundo Aldrich (1987), a relação entre a comunidade de plantas daninhas e as culturas pode variar de ano para ano e de local para local.

\section{LITERATURA CITADA}

ALDRICH, R. J. Predicting crop yield reductions from weeds. Weed Technol., v. 1, n. 3, p. 199-206, 1987.

BAILEY, W. A.; WILSON, H. P.; HINES, T. E. Influence of cultivation and herbicide programs on weed control and net returns in potato (Solanum tuberosum). Weed Technol., v. 15 , p. $654-659,2001$

BELLINDER, R. R. et al. Weed control and potato (Solanum tuberosum) yield with banded herbicides and cultivation. Weed Technol., v. 14, n. 1, p. 30-35, 2000.

BELTRANO, J.; CALDIZ, D. O. Effects of johnsongrass (Sorghum halepense L. Per.) densities on potato (Solanum tuberosum L.) yield. Pesq. Agropec. Bras., v. 28, n. 1, p. 21-24, 1993.

BOYDSTON, R. A.; VAUCHN, S. F. Alternative weed management systems control weeds in potato (Solanum tuberosum). Weed Technol., v. 16, n. 1, p. 23-28, 2002.

CIUBERKIS, S. et al. Effect of weed emergence time and intervals of weed and crop competition on potato yield. Weed Technol., v. 21, n. 1, p. 213-218, 2007.

EBERLEIN, C. V. et al. Efficacy and economics of cultivation for weed control in potato (Solanum tuberosum). Weed Technol., v. 11, n. 2, p. 257-264, 1997.

EMPRESA BRASILEIRA DE PESQUISA AGROPECUÁRIA - EMBRAPA. Centro nacional de pesquisa de solos. Sistema brasileiro de classificação de solos. Brasília: Embrapa Produção de Informação; Rio de Janeiro: Embrapa Solos, 1999. 412 p.
HUTCHINSON, P. J. S.; TONKS, D. J.; BEUTLER, B. R. Efficacy and economics of weed control programs in glyphosate-resistant potato (Solanum tuberosum). Weed Technol., v. 17, n. 4, p. 854-865, 2003.

JAISWAL, V. P. Crop weed competition studies in potato. J. Indian Potato Assoc., v. 18, n. 3, p. 131-134, 1992.

KNEZEVIC, S. Z. et al. Critical period for weed control: the concept and data analysis. Weed Sci., v. 50, n. 6, p. 773 786, 2002.

KOZLOWSKI, L. A. et al. Período crítico de interferência das plantas daninhas na cultura do feijoeiro-comum em sistema de semeadura direta. Planta Daninha, v. 20, n. 2, p. 213-220, 2002.

KOZLOWSKI, L. A. Período crítico de interferência das plantas daninhas na cultura do milho baseado na fenologia da cultura. Planta Daninha, v. 20, n. 3, p. 365-372, 2002.

LIEBMAN, M. et al. Tillage and rotation crop effects on weed dynamics in potato production systems. Agron. J., v. 88, n. 1, p. $18-26,1996$

LOCKE, M. A.; REDDY, K. N.; ZABLOTOWICZ, R. M. Weed management in conservation crop production systems. Weed Biol. Manag., v. 2, n. 3, p. 123-132, 2002.

MUELLER-DOMBOIS, D; ELLENBERG, H. Aims and methods of vegetation ecology. New York: John Wiley \& Sons, 1974. 547 p.

MUHAMMAD, B. Impact of weed competition on potato production. Pakistan J. Agric. Res., v. 14, n. 1, p. 64-71, 1993.

PITELLI, R. A. Interferência de plantas daninhas em culturas agrícolas. Inf. Agropec., v. 11, n. 129, p. 16-17, 1985.

PITELLI, R. A.; DURIGAN, J. C. Terminologia para períodos de controle e de convivência de plantas daninhas em culturas anuais e bianuais. In: CONGRESSO BRASILEIRO DE HERBICIDAS E PLANTAS DANINHAS, 15., 1984, Belo Horizonte. Resumos... Piracicaba: 1984. p. 37.

VANGESSEL. M. J.; RENNER. K. A. Effect of soil type, hilling time and weed interference on potato (Solanum tuberosum) development and yield. Weed Technol., v. 4 n. 2, p. 299-305, 1990.

VELINI E. D. Interferência entre plantas daninhas e cultivadas. In: SIMPÓSIO SOBRE HERBICIDAS E PLANTAS DANINHAS, 1., 1997, Dourados. Resumos... Dourados: Embrapa/CPAO, 1997. p. 29-41.

VIDAL, R. A. et al. Nível de dano econômico de Brachiaria plantaginea na cultura de milho irrigado. Planta Daninha, v. 22, n. 1, p. 63-69, 2004.

ZOSCHKE, A.; QUADRANTI, M. Integrated weed management: Quo vadis? Weed Biol. Manag., v. 2, n. 1, p. 1-10, 2002.

Planta Daninha, Viçosa-MG, v. 26, n. 1, p. 83-91, 2008 